\title{
Online Service Delivery in Survey Offices: Step towards e-Land Administration
}

\author{
Susheel Dangol, Prakash Joshi, Tanka Prasad Dahal \\ susheeldangol@nepal.gov.np, lightjoshiji@gmail.com,tpdahal@gmail.com
}

\section{KEYWORDS}

Online service, NeLIS, MeroKitta, e-land administration

\begin{abstract}
Survey Offices established at the districts under Survey Department are supporting with cadastral survey and the updating the parcels according to the land transactions. Almost all of the district offices among 131 of such are conducting its daily activities in digital environment. At present all the district survey offices have their own server and individual desktop applications are running to conduct the daily activities. In the recent development, Survey Department has developed three tier client-server based system architecture where application and database server are managed in central server hosted in Government Integrated Data Centre and clients access these server to provide the service. This system has enabled to integrate all the cadastral data from district survey office to single central archive. "Nepal Land Information System (NeLIS)" for daily service delivery from the survey offices and "MeroKitta" to get online service facility from survey offices has been developed and implemented in few numbers of the survey offices and planned to replicate in further offices.
\end{abstract}

\section{BACKGROUND}

Survey Department, the National Mapping Organization of Nepal, is responsible for topographical survey, geodetic survey, cadastral survey, international boundary survey and also acts as National Spatial Data Infrastructure hub for the country. The department is also the governing body to regularize the production and use of spatial information. To conduct all these task, department has specific divisions and district survey offices (Figure 1).

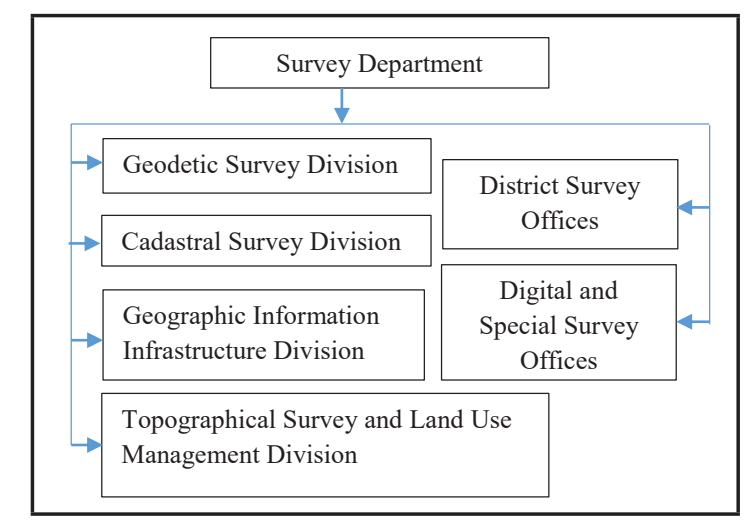

Figure 1: Organization structure of Survey Department. 
District Survey Office (SO) is responsible for the cadastral survey and updating of the cadastral data at district level. There exist 131 district survey offices including five special survey offices and one digital cadastral survey office.

Tasks of SOs are mentioned as follow;

- Management of cadastral documents

- Map print

- Parcel Subdivision

- Field book Print

- Plot register print

- Parcel integration

- Parcel boundary marking in ground

- Cadastral survey (New and Resurvey)

- Area Computation etc

\section{EXISTING SYSTEMS}

Survey Offices have different responsibilities according to the Terms of Reference defined by Survey Department. Some SOs have the responsibility of cadastral data update only while some offices have the responsibility of both cadastral survey and cadastral data update whereas some of the offices have only responsibility of cadastral survey.

According to the responsibility, survey offices are adopting different systems developed by the Survey Department. SOs which has the responsibility of cadastral data update is using Spatial Application Extension (SAEx) for executing their daily transactions and the SOs which is conducting Cadastal Survey digitally is using Parcel Editor (PE). This shows that the SOs which have the responsibility of cadastral data update and cadastral survey are using two different systems in same office.

Further, both of these systems are customized for Arc Map software. Hence, huge amount of investment was required for license purchasing and annual renewal of the license. The system developed as such is totally isolated in each work station. To some extent, local servers were maintained in the office and databases were stored in it and the workstation access to these servers during transaction. No central server and access system available in these systems. The business process can easily be bypassed by not using the tools available in the system but using the standard tools of Arcmap. Hence, history of the transaction and the task $\log$ cannot be stored and maintained. Hence it could not be monitored from the central system. The personal geodatabase created are easily accessible and editable from any other third party software. So there is huge risk of data insecurity too.

\subsection{Spatial Application Extension (SAEx)} SAEx is specifically developed to handle the secondary data derived from digitization of the paper cadastral maps. Major focus of this system is to handle the updating part of the cadastral data. The cadastral data in the SO goes for parcel subdivision if needed during land transaction. This kind of updating task is conducted by this system in SO. The application deals with cadastral map printing as well. The major features of SAEx are;

- Digital archive of paper maps

- Cadastral map updating (parcel subdivision)

- Map printing etc.

This application does not care about the cadastral Survey and document preparation part.

\subsection{Parcel Editor Application}

Parcel Editor Application is specifically developed to prepare cadastral maps and database on the basis of primary field survey. The application is able to handle cadastral data updating and map printing facility. The platform for this application is ArcGIS9x and Windows7 operating system. The major features of this application are; 
- Multipurpose Cadastral data management (including data if topography and utility services)

- Parcel Subdivision

- Map printing

- Field book printing

- Plot register Printing

- Land owner and Tenant record management

- Land ownership record and certificate printing

- Land owner and tenant record management etc.

\section{PRESENT DEVELOPMENTS}

Survey Department from past few years initiated to develop and integrated system which can handle both field work and office work of SOs, i.e. preparation of cadastral map and database from the primary survey and cadastral data update during daily transaction. Survey Department initiated the system in order to enhance the efficiency of the office in context of service delivery and the performance of the offices. For this, the department developed "Nepal Land Information System (NeLIS)", the system which is based on Free and Open Source System (FOSS). Since its based on open source software, there is no need of license cost and annual renewal cost for software license. The only cost is the development cost and one time implementation. Besides this benefit, in this system, all the database of district offices are stored in one single database at central server whose backup is also maintained. The database is highly secured and the system can also be monitored from the centre. NeLIS is particularly developed to conduct the daily transaction and cadastral survey from the Survey Offices. Hence, this system is for internal official users. Besides, the department also developed an online system to provide information services to the citizens termed as "MeroKitta". Detail is discussed in following sections.

\subsection{System Architecture}

NeLIS is developed in client-server architecture (Figure 2). Application server, database server are maintained in Government Integrated Data Center (GIDC) which is secured by firewall. The backup of the entire database is also maintained at Disaster Recovery (DR) site of the GIDC. All the desktop users in the client part at the SO and GIDC server is connected through the private network.

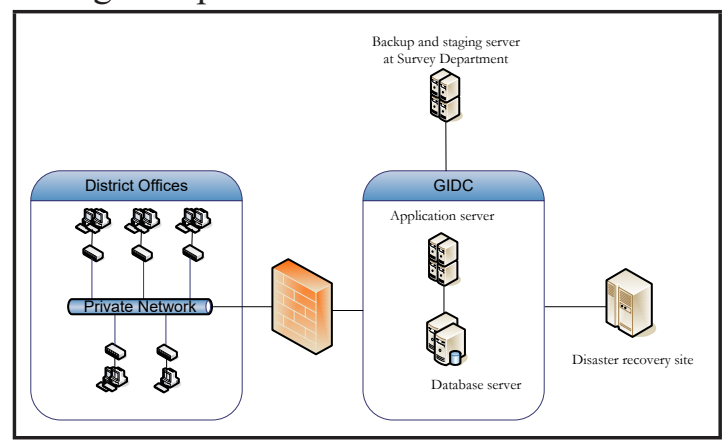

Figure 2: System architecture of Nepal Land Information System.

The cadastral database of whole country is single database managed in PostgreSQL. The client will use the desktop application which will run from the application server. The user accounts are managed within the system and the accessibility to the system and the privilege to the conduct the task for the users are properly maintained.

\subsection{1 "Nepal Land Information System (NeLIS)"}

NeLIS is the system developed to conduct the activities of the Survey Office in digital environment and in the client-server working mode. The client computer only use the desktop application of NeLIS which is running at the application server maintained at GIDC. These applications communicates with the database server, render the data in desktop, completes the transaction and then again stores back in the server. For example, the parcel subdivision request comes from the land revenue office or the citizen request 
for map print at the SO. When the request is received, the information provided is verified in the system and if the information is valid, the service is provided for the map print request. For sub-division, the system search for the parcel in the database, conducts the parcel editing as per the requirement, inputs required information regarding land owner and other related information and delivers the service (Figure 3). All these workflow is maintained digitally.

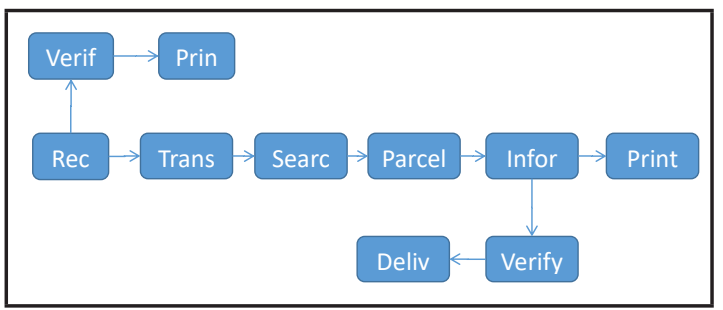

Figure 3: Business workflow throughNeLIS.

Besides the service delivery, the system also provides necessary information like total number of transaction according to the types of transaction like map print, parcel sub-division, field book print, total amount of revenue etc.

\subsubsection{Requirements at the Survey Offices for implementation of NeLIS}

Requirements can be categorized in two sectors as physical infrastructure and database structure. Besides the strong infrastructure at the central server, the client side at the district office requires sufficient computers which are well networked within the office. Networking with firewall and network switch/router is minimum requirement at the survey office. The network of the office is linked to GIDC server with private network (intranet). This network infrastructure strengthens the security of the data and enhances the service delivery through quick and uninterrupted real-time access to database.

Another very crucial requirement is data cleaning and updating. Since this system migrates existing geodatabase, it uses standard rule to migrate the data to this system. Hence, the geodatabase should be very clean and update for full migration of the data successfully. For example, no fields in the geodatabase should have null value. Like, district code, then VDC code, parcel key should not be null value and if it is so, then the particular parcel will not be migrated and there will be void in the NeLIS system. Also, the database should not have any sliver polygon or null polygon. The topology need to be checked an all the errors should be cleaned before migration. If these errors are not eliminated, then the error will arise during the land transaction.

\subsection{Information Architecture}

The information and services to the public, bank or local level is provided through the internet connectivity whereas the internal transaction process in the $\mathrm{SO}$ is conducted through intranet connectivity. The database is connected through NeLIS desktop application via intranet and transaction process is completed. For the information, the database is connected through https://nelis.dos.gov.np. For the public, bank or financial organization and local level, the information is accessed through https://merokitta.dos.gov.np. "Merokitta" communicates with "NeLIS" and "NeLIS" link with the database (Figure 4) and the service seekers get the service through the same "Merokitta" website.

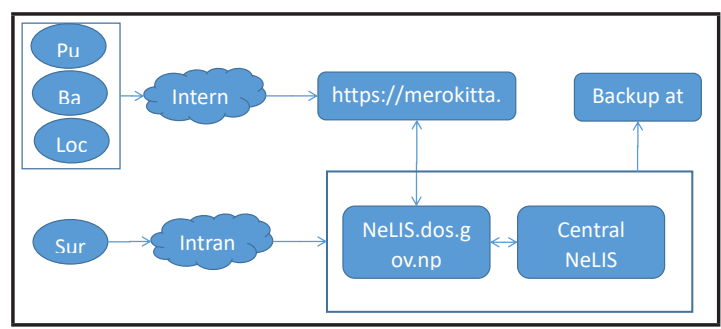

Figure 4: Information architecture.

\subsection{1 "MeroKitta"}

"MeroKitta" is the online system where the clients request for the service through the 
website https://merokitta.dos.gov.np. The client and track the status of the application for the service in the same website and also get the final deliver of the service for download in the same website again.

The system has two types of users. One is individual user who doesn't need any login credentials but need to provide the valid mobile number where SMS will be sent through the system regarding every middle process before final service deliver. Another user of the system is an institutional user which needs to get the login credential to receive the service. Figure $\mathbf{5}$ shows how the information is provided from the system.

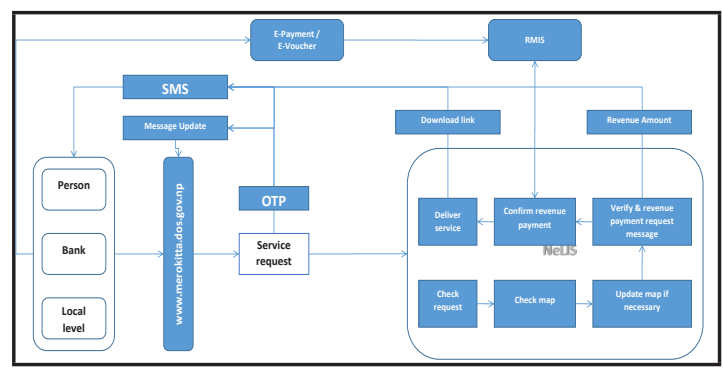

Figure 5: Workflow of information services.

\section{a) Receiving service by individual users.}

The individual users need to fill up the minimum necessary information required to receive the service. During the application, the user needs to provide the valid mobile number and also upload the scan copy of land ownership certificate and citizenship certificate. The client should select the office where he/she is requesting for the service, which local level and what service he/she is requesting for. The client should also provide the information about initial local unit information, ward number, map sheet number and parcel number of the parcel for which the service is being requested.

After the service request has been lodged, the system will send the SMS informing that the application has been initiated and also providing One Time Password (OTP). The mobile number and the OTP will be used in the whole system to check the status of the transaction and final download of the service. The user at the SO verifies the information of the parcel provided with the database of the office and sends the SMS requesting for the revenue payment. The client can pay the revenue through online payment system inbuilt in the "MeroKitta" system, or any other e-payment system or the client can print the electronically generated bank voucher and visit the nearby bank to deposit the revenue.

The status of the payment is shown in the "NeLIS" side of the office users. After the payment has been verified, the SO users upload the document and the client receives the SMS regarding finalization of the service and request for download of the service. The client will receive the message about every step of the transaction in the mobile number provided during application for service. Also, the client can check the status of the transaction and download of the final product at https://merokitta.dos.gov.np by using the same mobile number and OTP provided in this mobile number.

\section{b) Receiving service by institutional users.}

The institutional users are banks, financial organizations or local level offices. These organization need to request for the user credential through the system. The user needs to request for user credential through the provided system. During the application, they need to confirm in which SO they are applying for the service. The Local System Administrator (LSA) at the SO will verify the application and Chief System Administrator (CSA) will approve the application. After this, the client will receive the login credential with the use of which, the organizations can receive the services from this online system. After login in the system, all the other process 
is same as the individual user does. But the institutional user can request for the bulk amount of request one at time for many clients.

\section{PRESENT STATUS AND FUTURE PLAN}

This type of client-server architecture based system is implemented in survey offices for the first time. In the fiscal year 2077/78 NeLIS and MeroKitta is implemented in ten survey office namely, Kalanki, Lalitpur, Bhaktapur, Dillibazaar, Chabahil, Tokha, Sankhu, Manamaiju, Rasuwa and Dolakha. For coming fiscal year, 2078/79 the implementation of the system is planned for thirty survey offices next year. The remaining office will be implemented accordingly in following years.

\section{BENEFITS OF "NeLIS" AND "MEROKITTA"}

Development and implementation of "NeLIS" and "MeroKitta" has many benefits and positive implications against the present digital system being used in the SOs major of which are discussed in the sections below.

\subsection{Technically strong infrastructure}

Since the system is based on the client server architecture and with the concept of central server for application and database, there is no hassle for server management at the individual SOs. All the data from every SOs are stored in the central single database in PostGre SQL server. The client does not have direct access to the database and hence enhances the security of the database. Each and every step taken by the users in the system are recorded and history is maintained too. This function controls the fraud transactions. Further, the system and every transaction at any of the survey office can be monitored from the central office too. The provision of super admin user has the privilege to check all the activities at the office. This makes the client users to be reluctant to do the fraud transactions.
Since the system is working on the base of application server, every survey offices use the same version of the system in contrary to the different versions being used in present system at the offices. If the new updated version is available then all the system at client part will receive the message about availability of the update version and the client can just update the system to newest version. Developer or the support from the center doesn't need to provide update package individually to the survey offices. With this client-server architecture, all the district offices will be working in same single database and same single software from the server. But the particular office will be provided access to the respective data only and cannot view or edit the data of other office. But, if the legal provision is enabled, then in future, the access and permission for different offices can be granted from super admin analyzing the work load of that office. For example, if survey office Lalitpur has huge volume of task and having problem in conducting the transaction in due time because of any circumstances, then the job can be transferred to other district office where there is very less work load. But this kind of facility needs to be explicitly described in the act.

\subsection{Support in E-land Administration}

This is the first step taken by Survey Department for providing online services to the client. Through the "MeroKitta" the client can request for the service through any common web browser or smart devises and also easily download the service from the browser itself or the device. On the other hand the internal office user also works on the base of central database. Further, the client also can conduct the payment through online medium.

At the NeLIS part, the land transaction starts when any request from Land Revenue Office (LRO) comes to the survey office. In the manual system, the client need to visit to SO 
carrying all the paper documents prepared from LRO. But in this NeLIS system, it has the provision to receive the request digitally. The system that is being implemented in the LRO needs to communicate with the NeLIS and send request to it. This provision is still need to be developed. This way, this system support in e-land administration which is inline with the objective of the Government of Nepal to enhance e-governance and support in building digital Nepal.

\subsection{Increasing Transparency and Reducing Corruption}

Since the user need to provide the mobile number during requesting for the service, all the messages are provided to the same mobile regarding every steps being taken in action for the request submitted. The client receives the message about successful submission of the application and OTP for tracking the request and downloading the service. The client can also check the status of his/her application through the "MeroKitta" website with the same mobile number and OTP. This gives the transparency in service delivery of the SO.

Also, in this service, the client doesn't need to pay cash at the office or request any other middle person for helping with getting the service. Client can directly pay through the e-payment system inbuilt in the system or use any other online payment system or print the bank voucher and visit nearby bank to pay the revenue. This type of e-payment reduces the corruption since it reduced the involvement of the middle man.

\subsection{Reduction of government investment}

This online service delivery system is based on the free or open source platform. There is no need to invest huge amount of money in procurement of proprietary software. Using of proprietary software also need a regular cost for renewing of the license, which in turn bring the need of regular cost for the software. Use of open source software reduces all these kinds of cost. The only cost that will incur is the cost of system development. Once the system is matured, no extra cost will be required. Hence, use of this kind of software will reduce the cost of using commercial software (ArcGIS in our context) and update of license as well.

Besides these stated benefits, there are lot more benefits from the implementation of the system like there is less use of paper, the client doesn't need to visit SO and stay in long queue to get the service, doesn't need to request for legal writers to help them for getting necessary application which need the extra money for their help besides the necessary revenue payment and many other minor benefits. This system directly supports in good governance in land administration sector of the country.

\section{CONCLUSION}

Survey Department has started to provide the online services to the clients from SO which has increased the efficiency of the service delivery from the SOs. The department has initiated the service from few number of SO and has plan to replicate the system to SO around the country in near future. With the implementation of the system, all the database of the SO around the country can be integrated to the single database through which the department can get the scenario of the existing land parcels, its rights, total area etc. from all over the country. At present the system has spatial data or the cadastral data where the data is migrated from the SAEx and both spatial and attribute data where the data is migrated from Parcel Editor.

In future, until the LRO and SO are integrated and one single land administration office is established, the system from both the office needs to be linked technically. NeLIS should be linked with the Land Records Information Management System (LRIMS) from LRO. 
This way, both spatial and attribute data will be linked from which a lot of information can be retrieved from the integrated system like total number of land owners, total area of land that the land owner is holding, land beyond the ceiling, different types of land, land owners etc.

Hence, implementation of this system in all the SOs will increase the efficiency of the service delivery of the SO. It plays important role in establishment of good land administration within country. This is the first step of the Survey Department towards online service and e-land administration. The system has still room for improvement which needs to be incorporated in future and make the system very powerful to implement in whole country.

\section{BIBLIOGRAPHY}

GoN, (1963). Land (Survey and Measurement) Act. Government of Nepal.

GoN, (2001). Land (Survey and Measurement) Rules. Government of Nepal.

GoN, (2016). The Directives on Land Survey and Measurement Including Map and Document Updating. Survey Department, Government of Nepal.

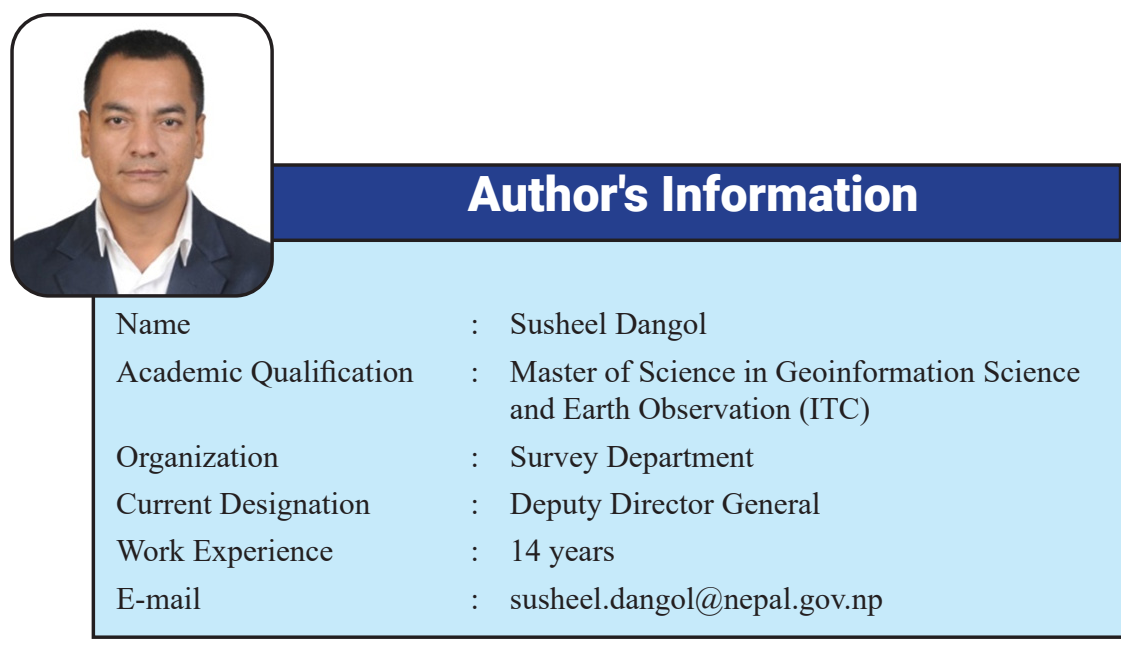

